\title{
2 Bronze Age Preludes: Foreigners and Fortifications
}

\section{I I N T R O D U C T I O N}

Many books on pre-Roman Italy have started their narratives with beginnings of the Iron Age. This phenomenon is probably caused by the fact that Bronze Age cultures and societies have always been problematical issues for 'Classical' archaeologists. This observation has been repeatedly made for Bronze Age Greece. On the one hand the Greek Bronze Age was considered as a heyday of civilization and could be shown to display links with Iron Age cultures and societies of Greece that were generally considered to be part of the domain of classical archaeology. On the other hand, the Bronze Age societies of Greece were separated from the later 'classical' world by the uncanny Dark Ages. Scholars studying the Greek Bronze Age, moreover, rarely ventured into the Iron Age or later periods of ancient Greece and students of the 'classical' world of Greece of the first millennium BC almost never looked into problems of the Bronze Age. The Dark Age was a great divide in the archaeology of Greece. Since this 'classic' phase in Greece was often believed to have contributed to the formation of western civilization in a significant way, the Greek Dark Ages were considered to be a period when a cultural dusk spread over the human world and the torch of civilization burned low.

A similar phenomenon can be observed in Italy, and especially southern Italy. The Italian Bronze Age was the domain of Italian paletnologia, whilst the Iron Age, pre-Roman and Roman periods of Italy were studied by those who practiced the archeologia classica. Different periods of early Italy were studied by different groups of archaeologists having different theoretical backgrounds, having different methods of research and using different chronologies. Intercommunication between prehistorians and classical archaeologists working in Italy, moreover, was rather limited. In this field too, there was a great divide between scholars studying the Bronze Age and students of the so-called 'classical' periods of ancient Italy.

Though the Italian Bronze Age was less spectacular than the Greek Bronze Age, it is generally perceived as a time of great flourishing. This was demonstrated for instance by intense contacts with Mycenaean Greece. The end of the Bronze Age (Italian: Bronzo Finale) and the beginnings of the Iron Age (with an almost complete absence of external contacts) constituted the Italian Dark Age. It separated the 'Mycenaeanizing' world of Bronze Age Italy from the Greek and Italic 'cultures', the formative phases of which were believed to have started in the late Iron Age (8th-7th centuries BC).

In southern Italy there was indeed a cultural and probably a demographic dip somewhere between the 11th and the 9th century BC. It should, however, be noted that it was mainly the coastal strip of southern Italy that displays traces of the presence of fairly complex societies and relatively populous settlements during the Late Bronze Age (LBA). It is on a limited number of coastal or sub-coastal sites with direct or indirect contacts with the Mycenaean world that much of the attention has focused: in many settlements in the inlands and uplands of southern Italy the Late Bronze Age was decidedly less spectacular. The image constructed for LBA southern Italy, was made on the basis of a literally marginal area: the coastal zone. What characterizes the Italian Dark Age is a decrease in, or a much lower visibility of the contacts with the southern Balkans, present-day Greece included.

The Dark Age dip in Italy, therefore, was basically created as an analogy to the Greek Dark Ages and was at least partially a figment of the imagination of the archaeologists. Dating based on assumed 
stylistic development of the Mycenaean pottery found at Italian sites lengthened the transition period between the Italian Bronze Age and Iron Age in the same way as it lengthened the transition between both periods in Greece. ${ }^{1}$ The Dark Age seemed longer and considerably darker than it actually was.

A good cause can be made for considering the Italian Bronze Age and Iron Age as two subsequent, but closely linked phases without any significant break in between. As we shall demonstrate below, the Italian Iron Age was in many respects rooted in the Bronze Age. The elements of continuity that link both periods in Italy are numerous, whilst data suggesting a decisive break are very few indeed.

This chapter, therefore, serves as one of the two introductions to the main theme of this book. While the second introduction in chapter 3 deals with the land and the people, this chapter deals succinctly with the Bronze Age foundations of the Iron Age societies. It discusses the important changes in southern Italy that resulted in new societies characterized by an unprecedented complexity. These came into being in the course of the 2nd millennium BC. The following sections of this chapter give a short cultural and historical background to the first millennium BC which is the focus of this book. The Bronze Age, moreover, produced monuments some of which continue to be visible to the present day. These impressive monuments were also part of the Iron-Age, Archaic-Classical, Hellenistic and Roman landscapes. They must have been meaningful to the people living in southeast Italy in the first millennium BC. They still played a major role in the south-Italian folktales during the 19th and 20th century AD.

\subsection{FROM THE N E O I TH I C P R I O D T I L T HE LATE B R NZE A G E}

Southern Italy has a wide renown for its rich Neolithic cultures. Numerous traces of these have been found in the very fertile and alluvial northern plain of Apulia, generally known as the Tavoliere. Here, aerial photographs have revealed the presence of numerous compounds, predominantly dating to the Middle and Later Neolithic periods. ${ }^{2}$ Important Neolithic settlements have also been found in the undulating hills in the district around Matera and Altamura where the present-day regions Puglia and Basilicata meet. Here is the name site of the Middle Neolithic 'Serra d'Alto Culture' (4th millennium BC) with its elaborately painted wares (fig. 2.1). This was a predominantly agriculturist society preferring fertile areas that were rich in water, just as the Late Neolithic Bellavista-Diana Culture of the 3rd millennium BC with its often highly burnished, hard-fired wares. ${ }^{3}$

From about $2500 \mathrm{BC}$ onward the Neolithic world of southern Italy gradually changed into the 'Copper Age' (Italian: 'Eneolitico'). By about 1800/1700 BC the Italian Bronze Age is assumed to have started. The Early and Middle Bronze Age societies (Italian: 'Proto-appenninico' and 'Appenninico') seem to have preferred environments that belong to slightly more arid parts of present-day southeastern Italy, possibly because in those times the climate was more humid than in the preceding period. In the early Bronze Age the settlements are mostly small. The same holds good for the earlier phase of the Middle Bronze Age (MBA). Field surveys have revealed substantial densities of small Middle Bronze Age sites on the relatively fertile Salento isthmus between Taranto and Brindisi and in the coastal plain near Ostuni (c. $30 \mathrm{~km}$ northwest of Brindisi) where limestone formations come close to the surface (fig. 2.2). ${ }^{4}$ These small settlements mostly did not function contemporaneously, but can be related to

1 For the traditional chronology of Mycenaean wares see e.g. Furumark 1941, and Taylour 1958.

$2 \quad$ See Tinè 1983 and Jones 1987.

3 For Serra d'Alto and Bellavista-Diana Cultures, see
Radmilli 1974.

4 For MBA settlements on the Salento isthmus, see Ynterma 1993a, 145-150; for the Ostuni district, see Burgers et al. 1998. 


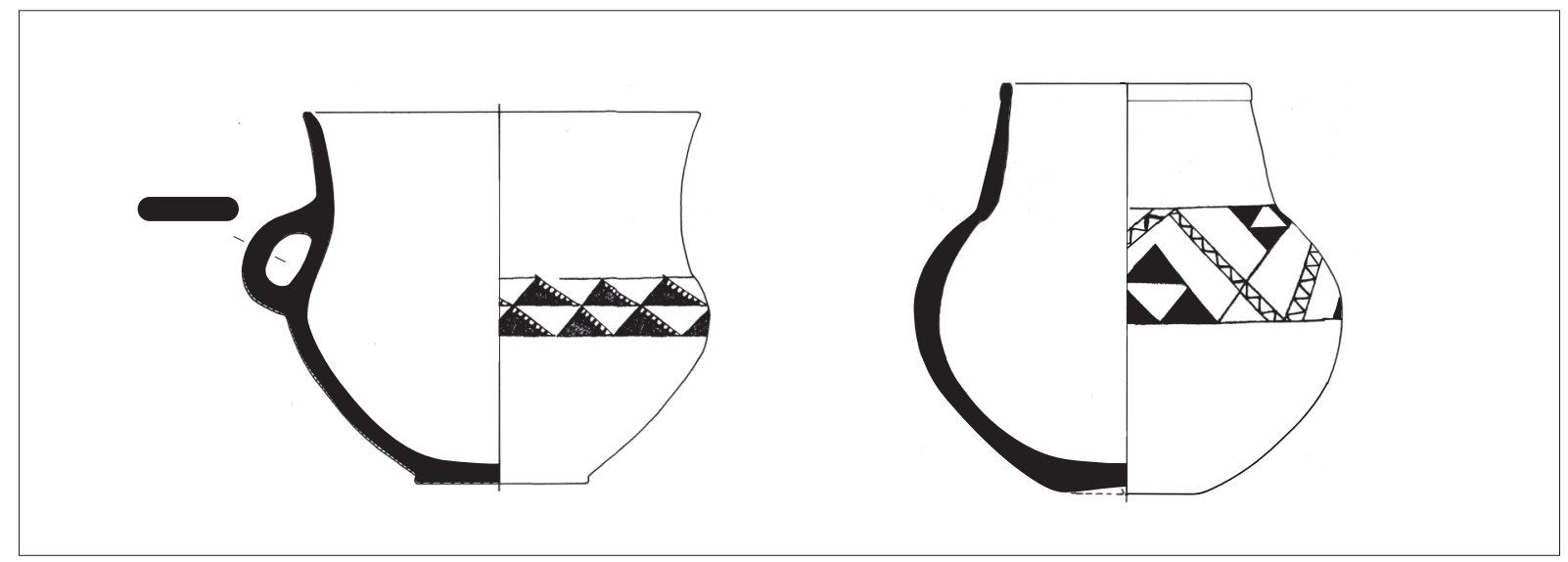

Fig. 2.1. Two painted vessels of the Serra d'Alto Culture from Leuca (south-Apulia); 4th millennium BC; after D'Andria 1978.

one or two groups that shifted their hut settlements regularly. Pollen cores suggest that slash and burn techniques were used in order to reclaim new agricultural plots, when the returns from the existing field diminished. ${ }^{5}$ They undoubtedly practiced agriculture, but their subsistence strategy seems to have been based predominantly on pastoralism. ${ }^{6}$

In addition to these relatively short-lived and constantly 'moving' villages, settlements of more permanent nature began to arise. This happened in the course of the Middle Bronze Age. This new type of settlement, moreover, was not abandoned after one or two generations. Several of these were inhabited for many centuries. This means that the relation between settlement and landscape changed drastically in the Middle Bronze Age. The predominantly dynamic human landscapes of the Early Bronze Age stabilized into landscapes in which manmade elements such as settlements and tilled fields often had a 'fixed' place. The results of palaeobotanical and archaeozoological research suggest other innovations that tie in with the more permanent character of the settlement: in the animal husbandry of these sites pigs increased at the cost of the often transhumant ovicaprines, whilst the ample presence of vegetables, cereals, olive pips and other tree crops shows that agriculture was important to these larger settlements of the Middle Bronze Age.

The rise of these larger settlements is indicative of an increasing complexity of the local societies of southeastern Italy during the period under discussion. ${ }^{8}$ Other signs suggesting considerable changes in socio-political organization are the defences. Well before the end of the Middle Bronze Age quite a number of settlements were surrounded by fortifications, especially in Apulia.. Moreover, the earliest burials indicating increased social stratification also date to the more recent phase of the Middle Bronze Age. Since the new, larger settlements coexisted with smaller settlements, their emergence also marks the birth of a distinct settlement hierarchy in southeastern Italy. Examples of such larger MBA settlements are the earliest phases of the sites of Torre Mordillo and Broglio di Trebisacce in northern Calabria, Toppo Daguzzo in northeastern Basilicata and Rocavecchia in southern Apulia. ${ }^{10}$ These are

5 Harding 1999, 93; cf. Di Rita / Magri 2009, 301-302

6 Bianco 1985 and Veenman 2002.

7 For agriculture at Broglio di Trebisacce, see Peroni 1989.

8 For settlements of different sizes in the Sibaritide, see Peroni 2004
9 For MBA fortifications, see Peroni 1989, 109, Cazzella 1991, Pagliara 2005, Scarano 2009.

10 For Broglio di Trebisacce, see Peroni / Trucco 1994; for Toppo Daguzzo, see Cipolloni Sampò 1986; for Rocavecchia, see Pagliara 1995, 2002, 2005, and Guglielmino 1996 and 2002. 


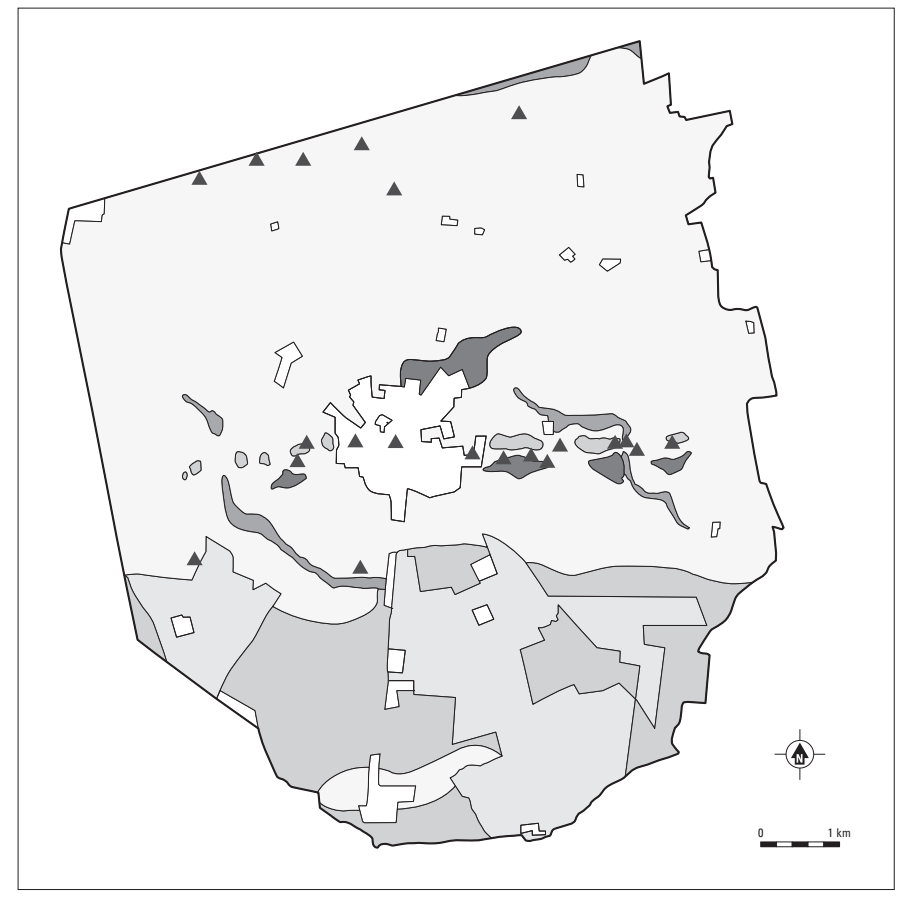

Fig. 2.2. Middle Bronze Age settlement patterns near Oria (Brindisi area), south-Apulia; field surveys VU University Amsterdam; after Yntema 1993a.

believed to have been fairly populous: Peroni suggests that they had hundreds of inhabitants. ${ }^{11}$ Since these sites continued to be inhabited to within the Late Bronze Age or even the Iron Age, the traces of MBA occupation are often very modestly preserved.

This Middle Bronze Age - currently indicated in Italian archaeology as the 'Cultura appenninica' - has often been characterized as a period in which pastoralism continued to prevail. Since this 'Apennine' culture displays a considerable degree of uniformity over large parts of Italy, there may be some truth in this view. ${ }^{12}$ Interregional contacts must have been frequent and transhumance and forms of nomadism, i.e. moving around with sheep, goats, pigs or cattle, is at least one way to attain cultural uniformity over large areas. But since it is also seen as a period of increasing stability in habitation patterns, i.e. of a decidedly more sedentary way of life, agricultural activities are likely to have acquired an increasing importance in peninsular Italy in the course of the Middle Bronze Age. ${ }^{13}$ It was also a period that displays a considerable degree of dynamics in other fields (e.g. social stratification, settlement hierarchy).

Another new phenomenon that can be observed in the Middle Bronze Age was the rise of regular and steadily intensifying contacts with the eastern Mediterranean. If Minoan and Mycenaean ceramic evidence can be trusted, their start is indicated by a trickle of Minoan and early Mycenaean wares. These can be dated to the 16th and 15th centuries BC (fig. 2.3). These contacts between southern Italy and Aegean areas became rather frequent and intensive during the Italian Late Bronze Age that is characterized by a flood of Mycenaean pottery. ${ }^{14}$

It was during the Middle Bronze Age that a fairly gradual, endogenous change towards more complex and more sedentary societies coincided with external stimuli coming from the steadily intensifying contacts with the eastern Mediterranean, in particular with Crete (but only initially) and Mycenaean Greece. ${ }^{15}$ These contacts were not exclusively bilateral. They were part of a series of interdependent exchange networks that manifested themselves more clearly in the Late Bronze Age and spanned the Tyrrhenean, the Adriatic and the Ionian Seas. These appear to have been linked with comparable networks in the eastern Mediterranean. Together these phenomena resulted in the fairly complex societies that flourished in the coastal and sub-coastal areas of southern Italy during the Late Bronze Age.

11 For settlement hierarchy, see Peroni 1989, 141; for number of inhabitants, see Peroni 1989, 136.

12 For pollen evidence documenting Bronze Age pastoralism in northern Calabria, see Attema et al. 2010, 85.
13 More stable forms of settlement in MBA, see Bianco 1985, and Peroni 1989.

14 Vagnetti 1999, Van Wijngaarden 2002.

15 See Vagnetti 1982 and 1999. 


\begin{tabular}{lll}
\hline Generalized Chronology & English name & Current Italian names and terms \\
\hline c. $2500-2000$ BC & Italian ‘Copper Age' & $\begin{array}{l}\text { Eneolitico: } \\
\text { Cultura di Laterza }\end{array}$ \\
c. $2000-1700$ BC & Italian Early Bronze Age & Bronzo Antico: \\
& & Proto-appenninico \\
c. $1700-1350$ BC & Italian Middle Bronze Age (MBA) & Bronzo Medio: \\
& & Appenninico \\
c. $1350-1150$ BC & Late Bronze Age & Bronzo Recente: \\
c. $1150-900$ BC & (LBA) & Subappenninico \\
& Late Bronze Age/Final Bronze Age (FBA) & Bronzo Finale: \\
\end{tabular}

Table 2.1. Chronology and terminology of the South-Italian Bronze Age periods.

\subsection{THE LATE BRONZE AGE (C. I $350-$ I I 5 O B C )}

Since contacts with the southern Balkans and Aegean areas were among the crucial factors that led to the birth of the more complex LBA societies, it was especially in the coastal areas of southeast Italy (here these contacts were most intensive) that societal complexity became most pronounced. The coastline was littered with larger and smaller settlements displaying contacts with the Mycenaean world. Quite a number of LBA sites have produced dozens - and in a few cases even hundreds - of fragments of imported Mycenaean wares (fig. 2.4), whilst LBA metalwork of southern Italy displays evident signs of links with Aegean districts. ${ }^{16}$

The casual remark made in the preceding lines concerning the presence of both larger and smaller sites holds an important clue. It means that there were substantial differences in size between the various LBA settlements. Though it must be admitted that the first steps towards differentiation were made in the Middle Bronze Age (see paragraph 2.1), it was in the Late Bronze Age that substantial settlements with a population consisting of several hundreds of inhabitants emerged alongside small, dispersed villages consisting of groups of huts. ${ }^{17}$ This phenomenon suggests that the Late Bronze Age saw the rise of a more complex and more hierarchical settlement pattern. In this system the major sites probably functioned as central places with a decidedly regional character. ${ }^{18}$ Small settlements dating to the later phases of the Bronze Age have reportedly been discovered during field surveys. ${ }^{19}$ These are likely to have depended on larger centers in political, social and economic respects.

Unfortunately, the vast majority of LBA sites is not particularly well-documented. The most intensely researched and most intensely published site is undoubtedly Broglio di Trebisacce in northern Calabria. ${ }^{20}$. As a result of the floodlight thrown on this site, other LBA sites of southeastern Italy look rather bleak. There is, however, no reason to assume that Broglio di Trebisacce was a truly exceptional settlement in the period under discussion. It almost certainly ranked among the major settlements of its times. Other (sub)coastal sites of major importance may have been Torre Mordillo (northern Calabria), Taranto-Scoglio del Tonno ('Tunny Reef'), Rocavecchia (near the easternmost tip of Italy)

16 See Bietti Sestieri 1973 and 1988.

17 Peroni $(1989,136)$ suggests that the larger settlements of the Late Bronze Age may well have had more than a thousand inhabitants.

18 For central places in the Late Bronze Age, see Malone et al. 1994.
19 Small Late Bronze Age sites are reported by Vinson 1972 (border area between Puglia and Basilicata) and Rescigno 2001 (western Basilicata).

20 The most important publications on Broglio di Trebisacce: Peroni / Trucco 1994; Peroni / Vanzetti 1998. 


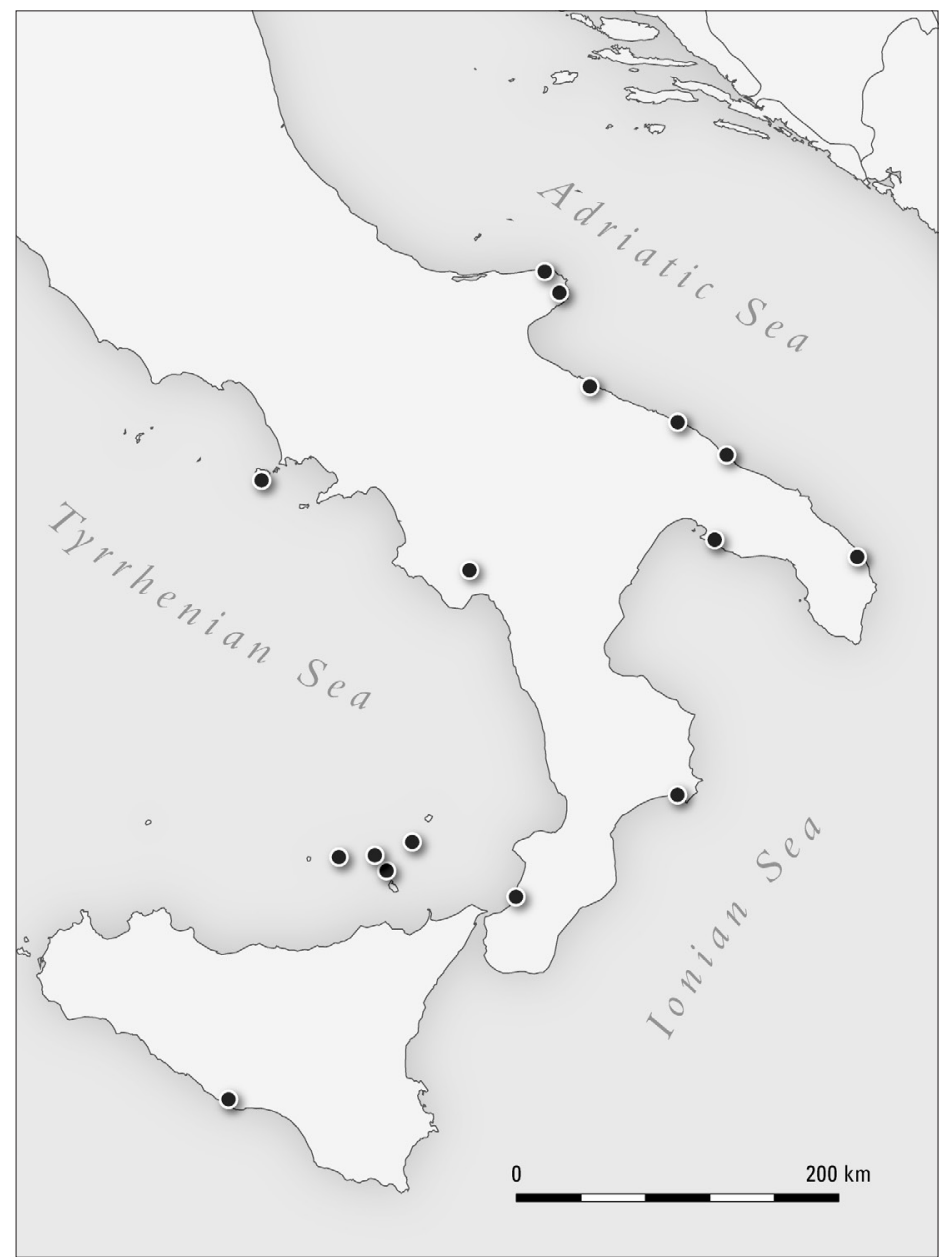
In view of the present state of research almost none of these has all these traits in unison. However, they are likely to have shared very similar sets of characteristics. One of the most recurrent features is the presence of fortifications. Many of the LBA sites of southeastern Italy actually can be shown to have had defences that enclosed the settlement area (fig. 2.6). These defences were at least hundreds of meters long and consisted in walls either made of carefully fitted irregular stones, or in earthworks containing piled up stones and earth (aggeres). The best examples are the fortifications of TarantoScoglio del Tonno demolished in the early years of the 20 th century ${ }^{24}$ and the still surviving walls of Torre Castelluccia, east of Taranto (fig. 2.6). The latter enclosed a flat-topped hill on the sea and a sizable area at the foot of the hill. ${ }^{25}$ These large defences constitute a very considerable input of time and effort. Therefore, they must have been made by a considerable group of persons that cooperated closely under the guidance of a central authority. The communities that produced them must, therefore, have consisted of minimally several hundreds of persons.

21 Peroni's list of larger centres of the Late Bronze Age also includes Torre Castelluccia, Porto Perone/ Satyrion (Taranto area), Punta Le Terrare (Brindisi), Amendolara, Broglio di Trebisacce, Francavilla Marittima, Castrovillari, Torre del Mordillo (all in northern Calabria) and Serra Ajello (on the Tyrrhenian Sea); see Peroni 1989, 111.
22 The most important publication on Scoglio del Tonno: Quagliati 1900.

23 If the large building in the centre of the plan is indeed the hall of a local chieftain (most current interpretation) the plan shows only the representative and perhaps redistributive part of the site of Scoglio del Tonno. 


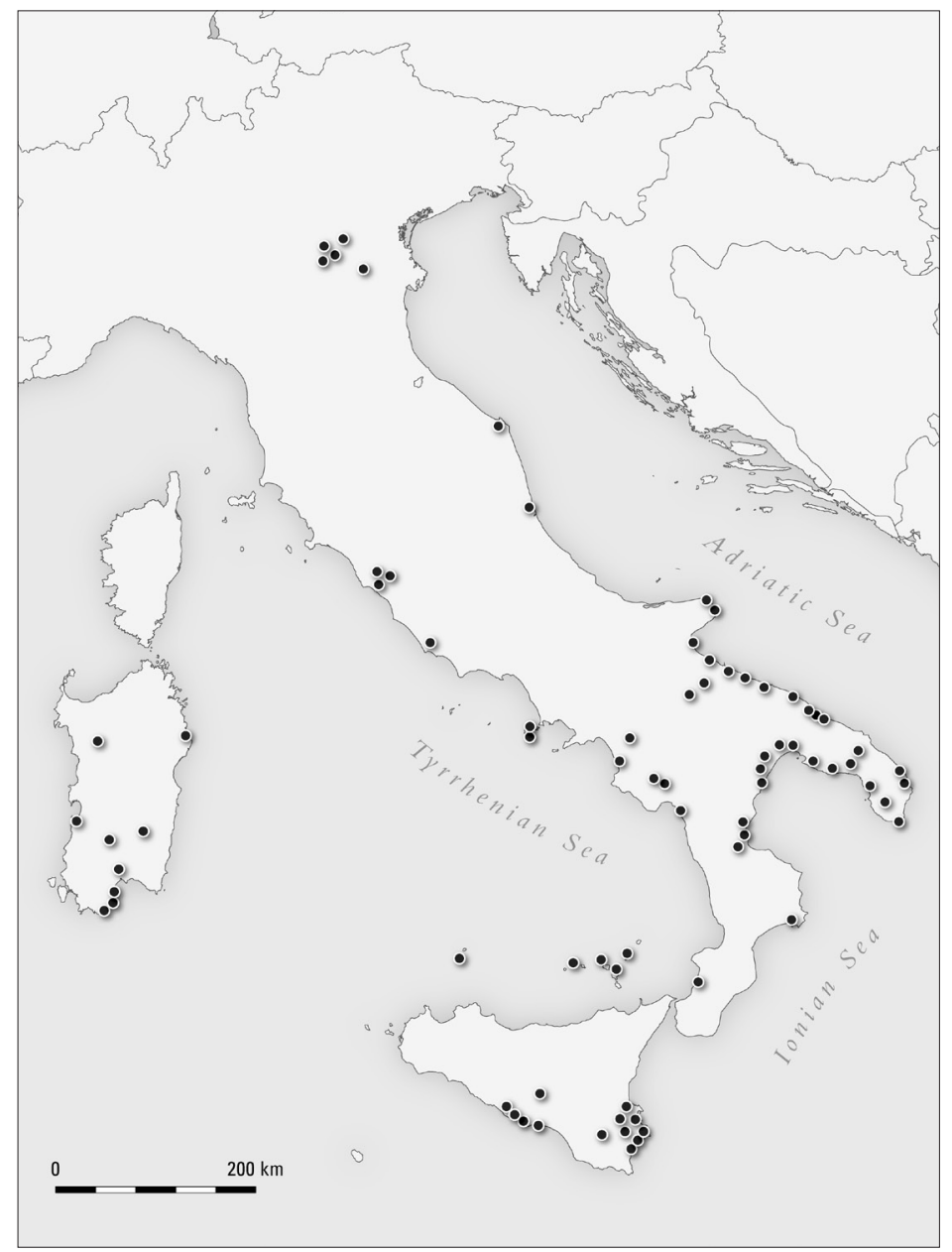

Fig. 2.4. General distribution of Mycenaean wares in Italy during the Bronze Age (16th11th century BC); based on Vagnetti 1999.

Because of their complex character these societies of the south-Italian Late Bronze Age are likely to have been socially stratified. Indications suggesting that this was actually the case, can be found in the architectural features encountered in the area enclosed by the walls. At Scoglio del Tonno, for instance, a large more or less rectangular structure was excavated with a width of more than 10 $\mathrm{m}$ and a length of well over $20 \mathrm{~m}$ (fig. 2.7). Whether it was the representative hall of a local chieftain and his retinue, a hall for communal meals or drinking parties, a large storage room or served still other functions is uncertain since the excavation was carried out in a fairly distant past (in 1899-1900). The rectangular building of Scoglio del Tonno, however, was much larger than the average rounded to oval LBA hut which had a diameter of approximately 2.50 to $3.00 \mathrm{~m}$. Therefore, it was certainly not the dwelling of an individual family.

Yet another sign of increased complexity can be found in the very large storage jars of the late Bronze Age. These vessels, called doli cordonati ('corded' dolia) in Italian, were often wheelmade. Fragments of these can be found in substantial quantities in various LBA settlements. ${ }^{26}$ They were up to $1.50 \mathrm{~m}$ high and well over $1.00 \mathrm{~m}$ wide, each having a capacity of some 500 to 1.000 liters (fig. 2.8). The recent excavations at the site of Rocavecchia suggest that such dolia (probably filled with olive oil) were standing in storage rooms in considerable numbers. ${ }^{27}$

The situation excavated at Rocavecchia which has a good parallel at Sicilian Thapsos, is reminiscent of those encountered in the storage areas of the contemporary Aegean palaces. The sheer presence and the large quantities of these large storage vessels suggest a very considerable surplus production indeed.

24 See Cento anni, 277.

25 It is unknown whether these fortifications completely surrounded the coastal settlements, since coastal erosion is strong on the limestone shores of Apulia. Geologists suggest that a 25 to 50 meters wide strip of land of land has been lost since the Bronze Age.

26 In the foothills around the plain of Sybaris (north-
Calabria), fragments of these dolia have been found at 12 sites during field surveys (see Attema et al. 2010, 114); on these dolia, see also Bianco / Orlando 1995.

27 Preliminary reports on Rocavecchia: Pagliara 1995, 2002 and 2005; Guglielmino 1996 and 2005; Scarano 2009. 


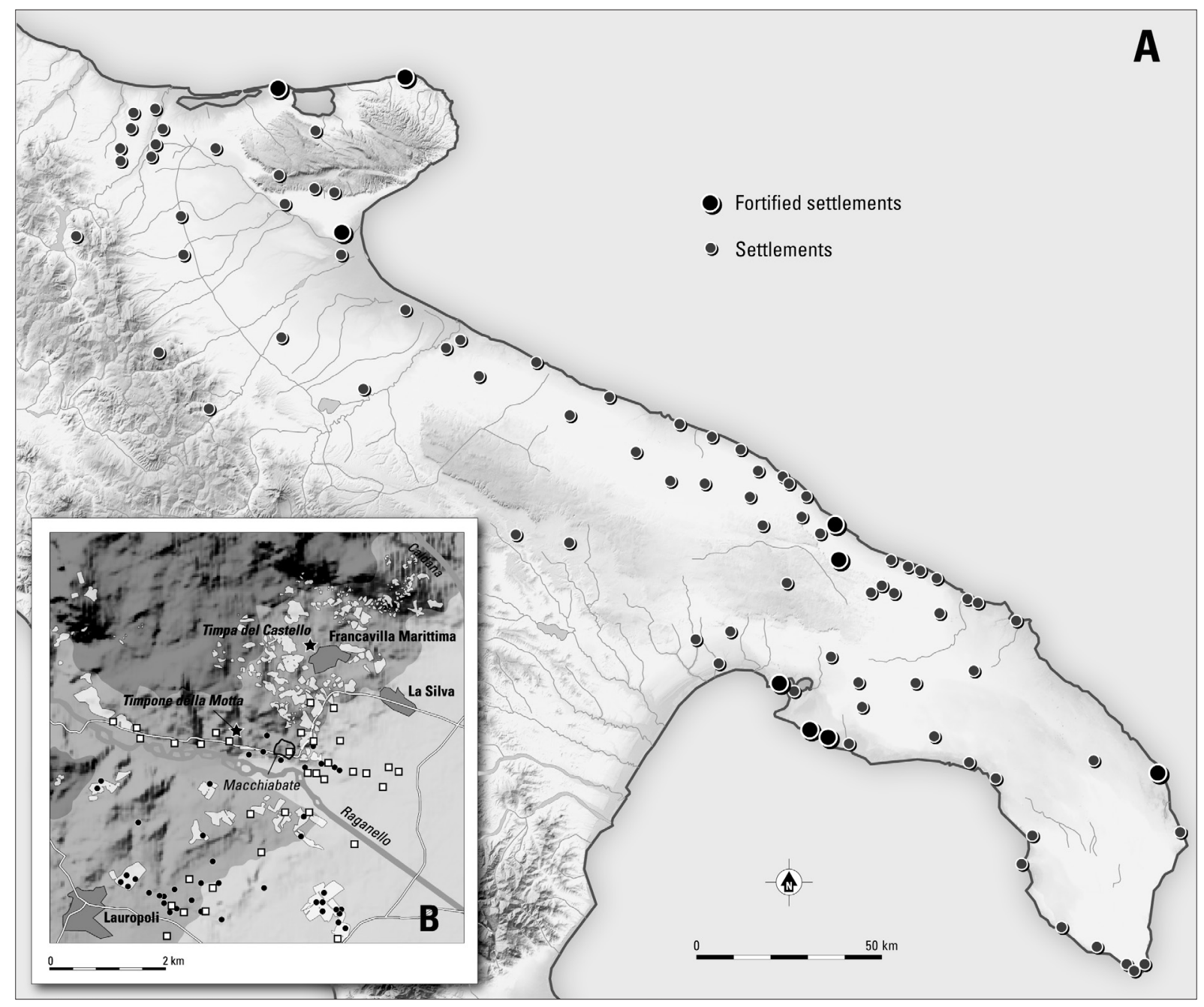

Fig. 2.5. Site hierarchies in the Late Bronze Age southern Italy: (A) Fortified settlements and non-fortified settlements in Apulia (based on Recchia / Ruggini 2009, fig.1); (B) Late Bronze Age in the plain of Sybaris (after Perono/Trucco 1994, 229).

Chemical analysis has demonstrated that the Rocavecchia dolia contained olive oil. Other types of objects that leave no traces in the archaeological record might have been stored here as well. These substantial surpluses were not only generated in the direct surroundings of the larger settlements of LBA southern Italy, but in the larger district of which it was the centre. The products stored in these centres were certainly not used exclusively for local or regional consumption, but must often have been articles that played a role in interregional and transmarine exchange. Settlements like Rocavecchia and Broglio di Trebisacce, therefore, suggest that the various local groups with their enlarged or new, often walled settlements did not thrive on subsistence economies. The storage areas in the larger settlements indicate that the LBA economy may well have been based on redistribution systems that spanned larger districts.

If every walled settlement was the centre of a more or less independent polity, the socio-political units were smallish. Since some of the LBA settlements stand out because of their sheer size and special finds, these are likely to have been at the top of the settlement hierarchy and may have been regional redistribution centres. It is, however, certainly wrong to see Rocavecchia, Scoglio del Tonno, Broglio di Trebisacce and other major walled settlements of the late Bronze Age as miniature versions of Mycenae or Pylos. The evidence from burials, for instance, suggests that the social structure of the south-Italian societies differed enormously from those of Mycenaean Greece. 


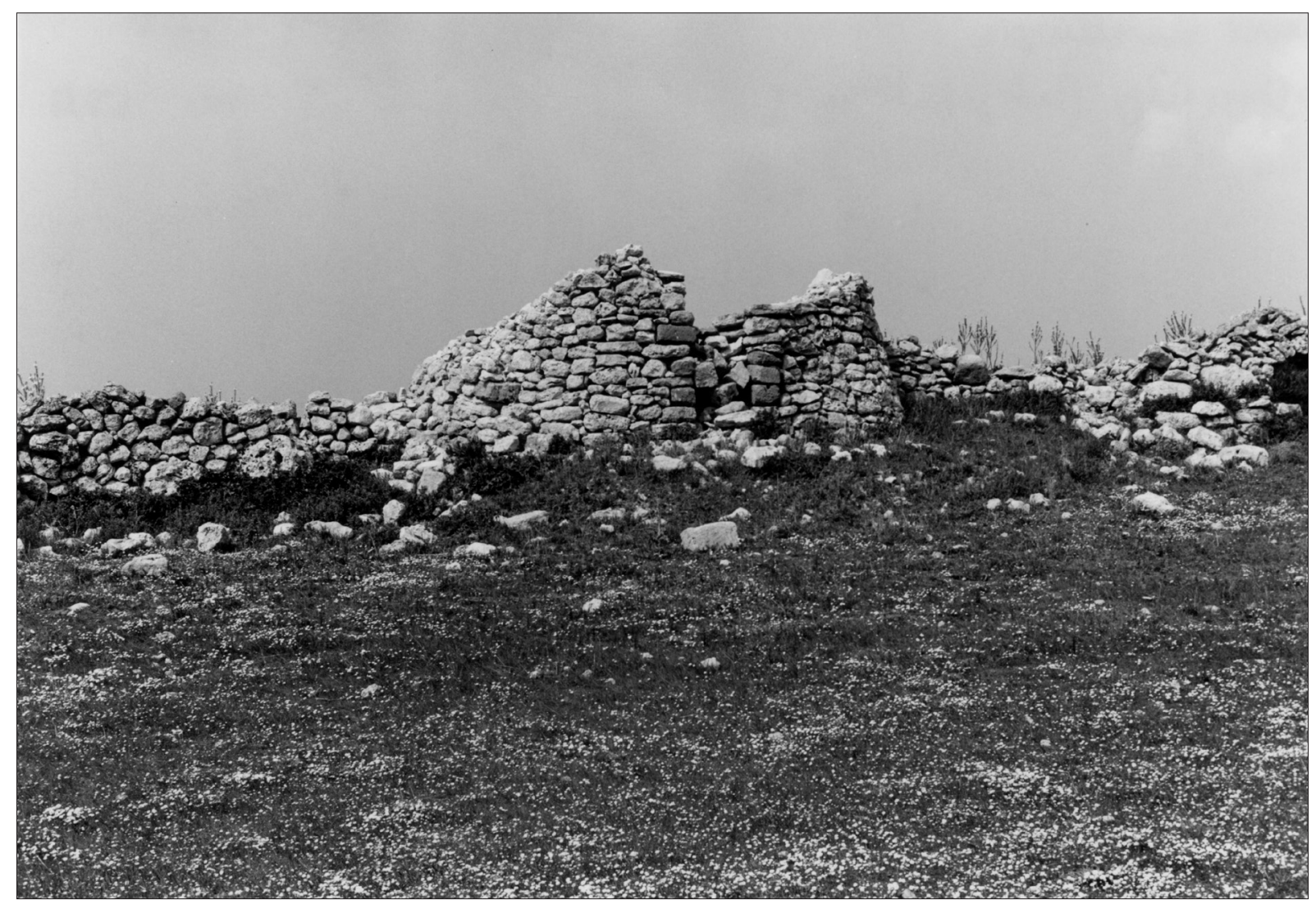

Fig. 2.6. Torre Castelluccia (Taranto area, south Apulia); Late Bronze Age fortifications in 1979 (archive ACVU).

Leaders of these fairly complex LBA societies also feature in the archaeological record. Although it is uncertain whether the long house of Scoglio del Tonno can be interpreted as an elite residence, the contemporary burial evidence of southeastern Italy contains quite a series of elite graves. There appears to be a variety of burial customs in the period under discussion. Fairly remarkable are the urnfields with individual cremation burials. The earliest burial site of this type in southern Italy was probably Canosa (northern Apulia). It contained well over 200 cremations dating between late 15th to 14th century and the 12th century BC. ${ }^{28}$ A second urnfield at Torre Castelluccia (Taranto) started in the Late Bronze Age and continued to well within the final phase of the Bronze Age. ${ }^{29}$ Whether these cremations were graves of a well defined social group within the settlement is uncertain.

The most spectacular burials of the Late Bronze Age were impressive monuments in stone. Many of these have been demolished, but in some places they continue to mark the landscape. These monumental burials mostly consist of large cist graves or even dolmens. Some of these were covered by huge tumuli, the so-called specchie. ${ }^{30}$ In these impressive structures the deceased were inhumed. Since

28 The Canosa urnfield had been reported in Lo Porto $1969 \mathrm{~b}$ and 1992a.

29 For urnfields in southeast Italy, see Müller Karpe 1961 and Vanzetti 2002.

30 Specchie (sing: specchia) are basically large heaps of stones. The term covers a variety of monuments that existed in southern Italy to well into the 19th century. The vast majority of these, however, have been demolished during the late 19th and the first half of the 20th century. At least some of these specchie can be shown to have been Bronze Age tumuli (mainly in the Salento peninsula). Heaps of stone (mostly smaller) in the Bari area, in the coastal districts of Basilicata and in northern Apulia sometimes turned out to be Iron Age burials (see chapter 4). Other specchie simply appeared to be large heaps of stones. 


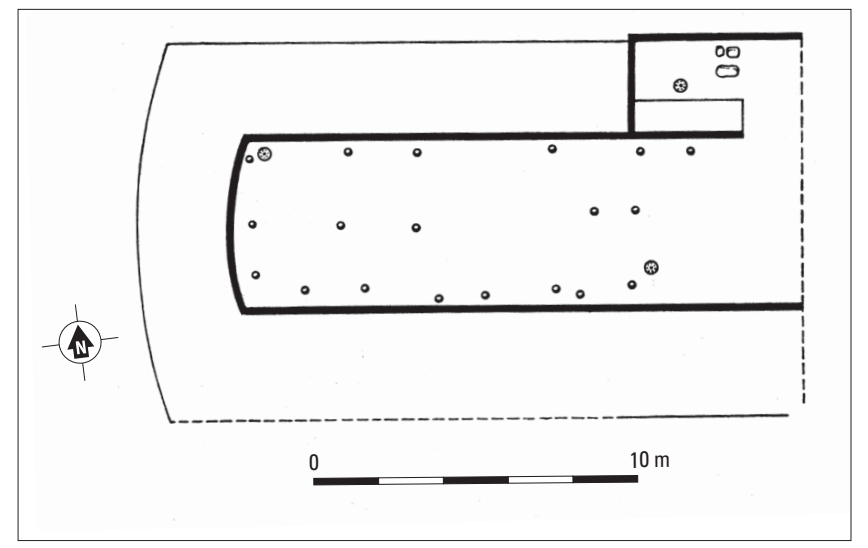

Fig. 2.7. Taranto-Scoglio del Tonno (south Apulia): Late Bronze Age longhouse within the fortifications (after Peroni 1989).

they were highly conspicuous, their contents have usually been robbed. The Torre Santa Sabina tumulus on the coast some 25 $\mathrm{km}$ northwest of Brindisi was still largely intact. ${ }^{31}$ It appeared to have a diameter of c. $15 \mathrm{~m}$ and contained 26 burials of which only the central grave (tomb 12) contained imported pottery from the Aegean and a bronze knife (fig. 2.9). It was probably the burial site of a dominant lineage of a kinship group focusing on the person in the central grave. Mycenaean wares also came from the now demolished, originally 6 $\mathrm{m}$ high Martucci tumulus (diameter c. $25 \mathrm{~m}$ ), situated some $6 \mathrm{~km}$ southeast from the site of Oria in the Salento district. These finds show that contacts with foreigners from the Aegean were important to the societies of southeastern Italy. The possession of objects referring to that Otherworld (e.g. Mycenaean pots and bronzes) and the introduction and display of new cultural modes linked with these objects probably enhanced the status of the local elites of southeast Italy.

These tumuli/dolmens occur in fairly limited numbers. ${ }^{32}$ This suggests that only a small group within the regional societies of southern Italy received a formal burial by means of inhumation in or near an impressive monument. The graves of the majority of the LBA population do not appear in the archaeological record. It is, however, problematical to relate the impressive burial monuments of the elites to specific settlements. None of them is actually in close proximity to a walled settlement. The now vanished Oria specchie may be a case in point. The Martucci specchia mentioned above was the largest mound of probably a cluster of tumuli. ${ }^{33}$ This cluster was in a relatively flat area some $6 \mathrm{~km}$ southeast of the fortified LBA settlement of Oria which was situated on a hilltop rising some $40 \mathrm{~m}$ above the surrounding countryside. Although definitely within view of the settlement, the burial site being at approximately one hour walking distance, may well have been on the brim of the manmade landscape (tilled fields, olive groves) that surrounded the fortified Bronze Age settlement of Oria. An almost identical tumulus existed approximately $6 \mathrm{~km}$ south of Oria (Schiavone specchia).

Such impressive monuments were symbols of influence and power. But they may also have served as territorial markers and have indicated the transition between the man-inhabited world of the settlement and its fields on the one hand and wild nature on the other hand. Since none of these elite burial sites of the late Bronze Age was close to a habitation area, their location was probably closely related to the meaning the Bronze Age populations of southern Italy assigned to the various elements of the territory or the landscapes that surrounded them. We can, of course, only speculate on the exact nature of these significances.

The objects found in the tombs stress the elite character of these LBA burials. The central burial of the Torre Santa Sabina tumulus near Brindisi contained i.a. pots from Aegean Greece (3 specimens) and warrior attributes. The same holds good for the Martucci tumulus near Oria. ${ }^{34}$ The possession of

31 Lo Porto 1963

32 For tumuli and dolmens in southeast Italy, see Biancofiore 1977, and Orlando 1995.

33 Neglia 1970.
34 Two stirrup jars in the Louvre Museum with provenance 'San Cosimo di Oria' actually come from the specchia Martucci that was partly demolished at about 1880 (Yntema 1993). 


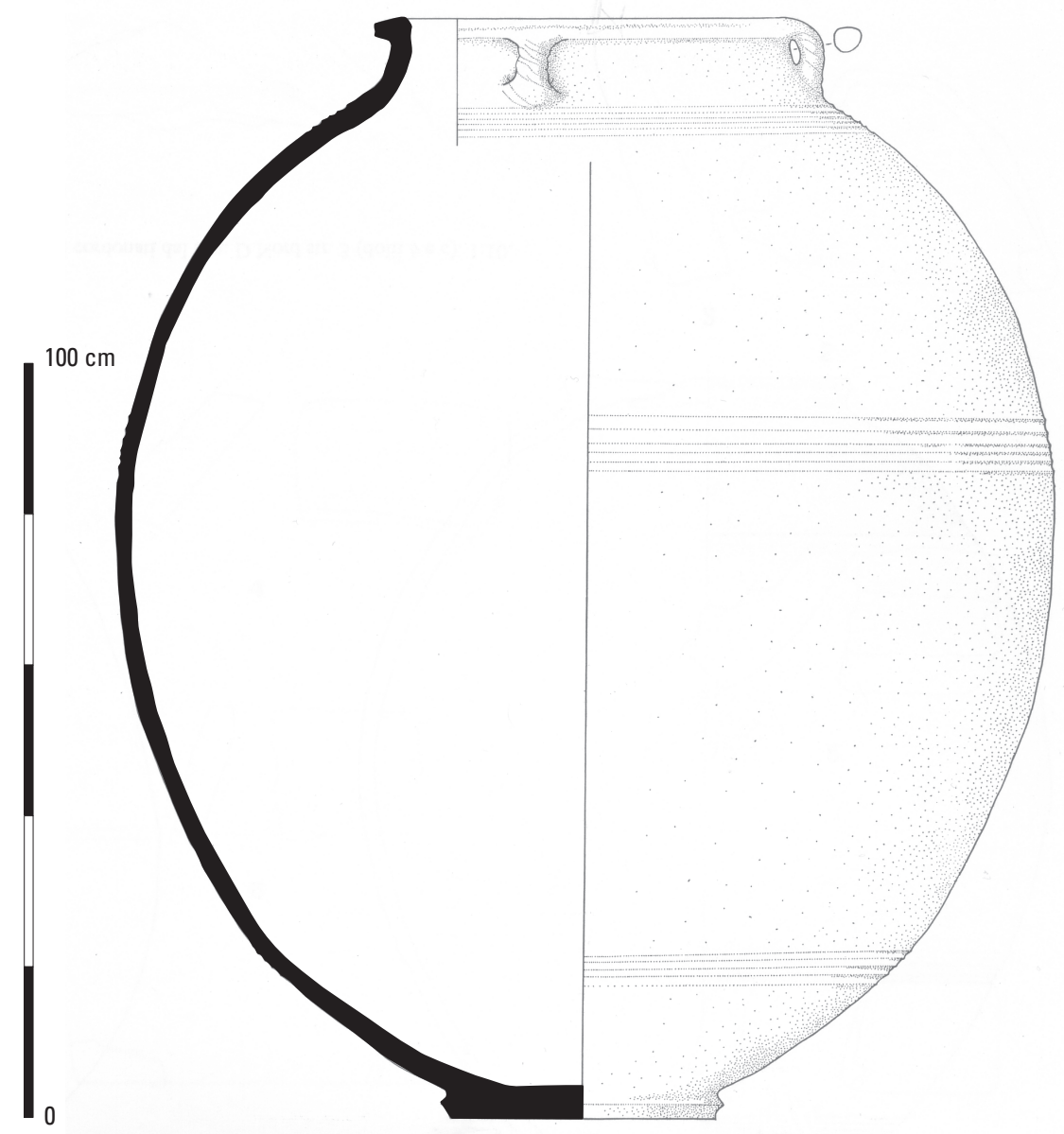

Fig. 2.8. Dolium with 'corded' decoration from Boglio di Trebisacce: after Peroni / Trucco 1994, pl. 66.

unusual, foreign looking objects was probably the prerogative of only a limited group. Since weaponry was found in several other elite tombs of southern Italy, ${ }^{35}$ the symbols and signs of a warrior status were also among the elements used by the elite to display their dominant position in the various regional societies of southern Italy.

Increased complexity can also be observed in craft. As usual, it is the omnipresent ceramics that supply the best evidence in this respect. The ceramics of the Middle Bronze Age were invariably handmade dark surface wares. Some pieces had incised decoration. These wares were invariably fired at relatively low temperatures in an atmosphere that was poor in oxygen. Such handmade dark surface wares are often indicated as impasto pottery in southern Italy.

Comparable handmade impasto ceramics continued to be made during the Late Bronze Age (the Subapennine wares; fig. 2.10). In addition to these, wheelmade and light surface wares made their appearance in southern Italy. The earliest specimens of these new ceramic classes date to the Middle Bronze Age and were decidedly imports stemming from Bronze Age Greece. ${ }^{36}$ Foremost among them were Mycenaean painted wares, the so-called Minyan Grey wares (both 'luxury table wares') and wheelmade container vessels (used for storage and transport). Soon, however, local wheelmade versions of all these ceramics were produced. The most spectacular series of elaborately painted wares was 

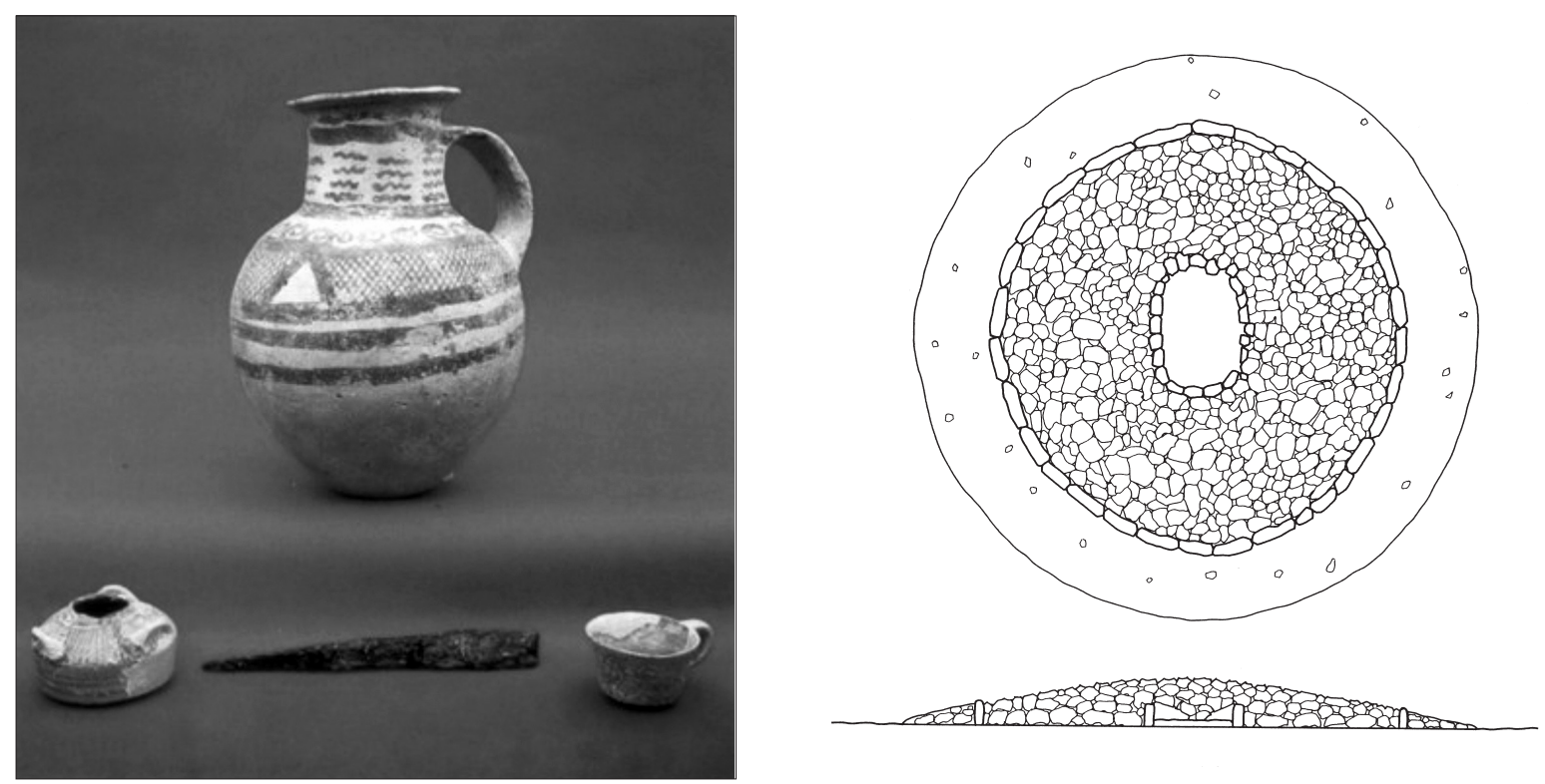

Fig. 2.9. LBA elites in south Apulia: Torre Santa Sabina (Brindisi area): tumulus and finds; after Lo Porto 1963 and courtesy Brindisi Museum.

unearthed at the site of Termitito on the Gulf of Taranto. ${ }^{37}$ Clay analyses of some samples of wares with strongly Mycenaean characteristics from both Termitito and the Campanian site of Eboli have shown that a fairly large percentage of such pots was actually made in southern Italy. ${ }^{38}$ Among these are specimens that on stylistic grounds cannot be distinguished from Mycenaean wares made in, for instance, the Argos area on the Peloponnesos (fig. 2.11).

These data suggest that Mycenaean potters were active at or near the sites of Eboli and Termitito and perhaps other LBA settlements of southern Italy. They made pots in exactly the same manner as they had done in the Aegean core areas of the Mycenaean world. Since a substantial percentage of the Mycenaean painted wares of southern Italy displays Italian fabrics, the production of Italo-Mycenaean wares was neither incidental, nor short-lived. Moreover, the elaborately painted wares were not the only class of 'Mycenaean' wares produced in Italy: highly burnished Minyan wares and doli cordonati were also made in fabrics characteristic of southern Italy. ${ }^{39}$ Therefore, it is unlikely that these ceramics were exclusively produced by imported craftsmen with Aegean roots. The craft of producing sophisticated wheelmade ceramics was almost certainly picked up by local potters.

This information implies a considerable, though not a total change in pottery production in southern Italy. The traditional impasto wares continued to be produced and continued to serve traditional purposes. The new ceramics with light-coloured clays, however, catered on new needs of the local societies, and especially those of the new elites. The painted Mycenaean and the burnished Minyan wares - both imported specimens and local versions - served predominantly as dining vessels. This shows that the use of these ceramics was based on the cultural significance of these pots and the activities associated with them. ${ }^{40} \mathrm{~A}$ similar observation can be made concerning the relatively thick-walled

37 For Mycenaean wares from Termitito, see De Siena 1986b.

38 The percentage of locally produced Mycenaean wares is up to $80 \%$ at Eboli (Campania); cf. Vagnetti / Jones
1988.

39 For clay analysis indicating regional/local production of doli cordonati, see Castellano et. al. 1996.

40 Van Wijngaarden 2002. 


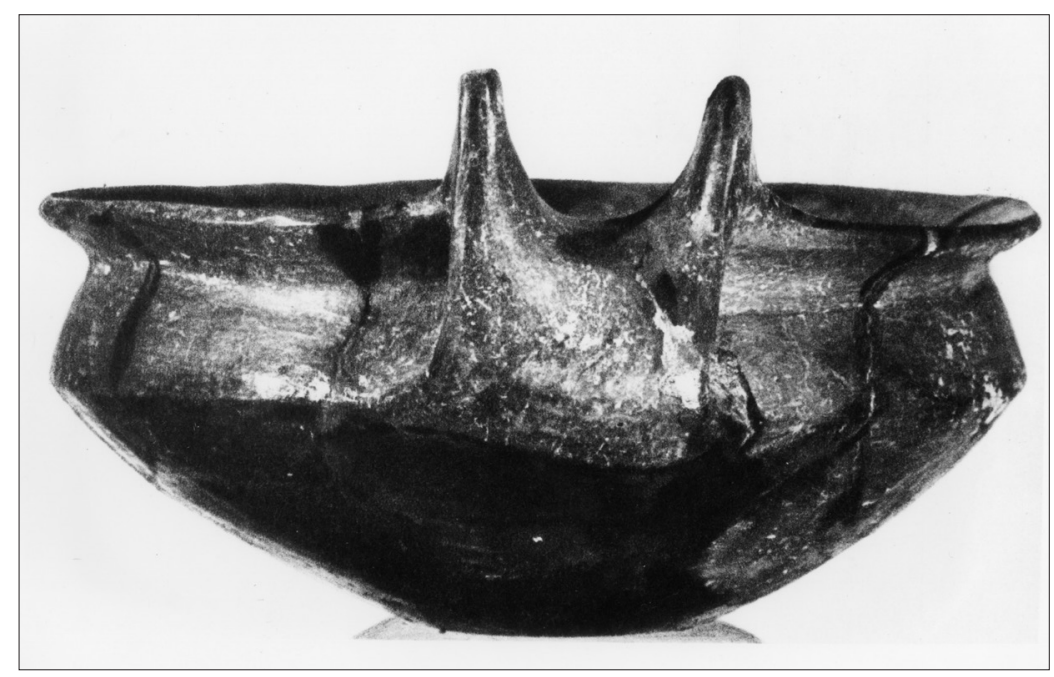

Fig. 2.10. Impasto scodella with horned handle from Torre Castellucia, Late Bronze Age. Photo courtesy Soprintendenza Taranto.

storage and transport vessels (the common dolia and the relatively rare amphorae). These were made in order to store the substantial surpluses produced in the Late Bronze Age and to transport the surplus products over considerable distances. These two activities were equally new to Bronze Age southern Italy.

The new types of ceramics that made their appearance in the Late Bronze Age demanded new, much more complicated techniques for the production of pottery. These were the first ceramics of Italy produced on the quick potter's wheel. They all had to be fired at considerably higher temperatures (c. $850-950^{\circ} \mathrm{C}$ ) than those needed for firing impasto wares $\left(\right.$ c. $\left.500-700^{\circ} \mathrm{C}\right)$. Whilst impasto can be made by firing the pots in a hole in the ground and covered with wood and branches ('bonfire' technique), the production of the dolia, the Italo-Minyan wares and the Italo-Mycenaean ceramics required a closed kiln containing separate chambers for combustion and for the firing of the pots. In order to attain the required effect of dark painted ornaments on light background of Italo-Mycenaean wares, moreover, oxidizing and reducing atmospheres had to be created in the kiln by the potter. This new firing process, therefore, required a good understanding of complicated pyrotechnics.

The rich series of bronze objects from LBA sites of southeast Italy also shows a considerable degree of innovation in craft. They display a wide and unprecedented variety of metal forms made for a wide variety of purposes. In addition to weapons such as swords, daggers, knives and arrows, there are personal ornaments (fibulae, pins, necklaces, bracelets) and tools for various purposes (e.g. axes, sickles, tweezers, scalpels, nails and fish hooks). These stem from various LBA sites (e.g. Scoglio del Tonno, Porto Perone, Coppa Nevigata and Punta Manaccora) and testify to the great skills and the specialized craftsmanship of the LBA bronze workers of southeastern Italy. ${ }^{41}$ Evidence from both Coppa Nevigata and Scoglio del Tonno suggests that the production of metal objects took place close to the dwelling of the local chieftain. ${ }^{42}$ The LBA smith, therefore, might have been part of the retinue of the local leader.

What escapes us in the present state of research is LBA religion. Hitherto no evident signs of sanctuaries or other traces of religious activities have been found in southeast Italy. The only type of objects that may be interpreted in this way are a few Mycenaean idols and locally made figurines from Scoglio del Tonno. ${ }^{43}$ It should, however, be observed that in LBA southern Italy other significances might have

41 For the variety of Late Bronze Age bronze objects, see,

43 For Mycenaean idols in Italy, see Taylour 1958, pl. 13. for instance, Biancofiore 1979, 151-157.

42 Peroni 1989, 251. 

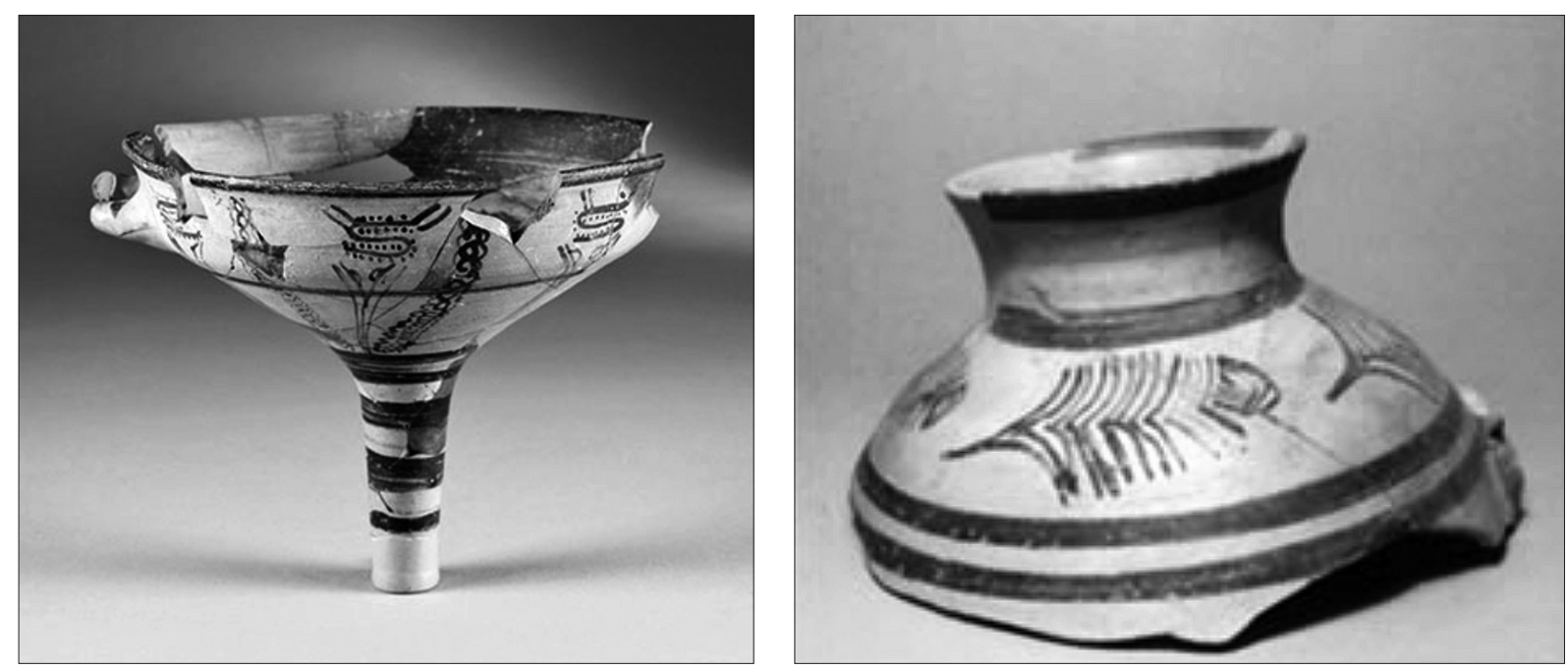

Fig. 2.11. 'Mycenaean' kylix (from Termitito) and jar (from Scoglio del Tonno); courtesy Soprintendenza archeologica della Basilicata and Soprintendenza archeological della Puglia.

been attached to Mycenaean idols and that other functions may have been performed by these objects than those currently assigned to them for Mycenaean Greece.

Summarizing the date presented above on the Late Bronze Age we can establish that the new elements that characterize the Late Bronze Age in southeast Italy are many. In the recent past much stress has been laid on the enormous intensification of long distance contacts as exemplified by the Mycenaean ceramics of Italy. These were important indeed and undoubtedly triggered a number of changes. More often, however, they were catalytic agents in the far-reaching changes that had their roots in the Italic Middle Bronze Age. The first signs of a substantial increase in socio-political complexity, for instance, pre-date the intense contacts with the Mycenaean world.

The Late Bronze Age witnessed the birth of distinctly hierarchical settlement patterns. Some centres had imposing fortifications. Settlements such as Broglio di Trebisacce, Scoglio del Tonno, Rocavecchia and Coppa Nevigata must have controlled fairly large areas containing also smaller settlements. In the same time social stratification increased: the local societies became more hierarchically structured. This new and more complex social structure of the south-Italian societies went hand in hand with the emergence of elites. These controlled the surplus production of their district which was collected in the central settlement. Moreover, they played an important role in exchanges between their groups and others. These new LBA leaders of southern Italy expressed their status by banqueting, using imported, elaborately painted or highly polished ceramic drinking vessels (Mycenaean wares, Minyan wares) or locally produced versions of these basically 'foreign' wares (Italo-Mycenaean, Italo-Minyan). They (and other persons linked to their house or their lineage) were buried in large and impressive tumuli well away from the settlements they had lived in. One of the sources of their wealth was the agricultural surplus production (probably mainly olive oil). These products were stored in the large container vessels, each with a capacity of 500 to 1.000 liters. In the larger settlements these filled substantial storage rooms that contained dozens of these large vessels. A room with 40 pots of this type could contain approximately 20.000 to 40.000 liters of olive oil.

As we have seen, these data suggest that the new societies that emerged in LBA southern Italy had basically redistributive economies. Long distance contacts and exchange with people coming from or living in other parts of the Mediterranean was vital to the complex LBA societies of southern Italy. These contacts did not take place exclusively between the south-Italian groups and people coming 
from Mycenaean Greece. The substantial uniformity in the repertoires of LBA impasto pottery and other types of objects over large parts of Italy indicates that contacts between the various districts of the Apennine peninsula were intensive. On the basis of the distribution of ceramics of Mycenaean type over Italy with substantial concentrations of these wares in southern Italy, Sicily, Sardinia and along the Adriatic coast of Italy, one must conclude that it was not exclusively olive oil that played a role in these exchanges. Metals are likely to have been another important item circulating in the LBA networks, ${ }^{44}$ whilst the finds from Fondo Paviani in the Po valley suggest that the exchange of Baltic amber also took place within these same circuits. ${ }^{45}$ These three categories leave their traces in the archaeological record, but articles of perishable nature such as, for instance, slaves and prestigious cloth may have circulated as well within these LBA exchange systems.

This means that some of the settlements that were important in these networks did not really owe their status to the products they had to offer themselves, but were important because they were on nodal points in the exchange networks. Rocavecchia not only had its olive oil: it is also the first stop in Italy for ships coming from Greece. The same site, moreover, is both at the beginning and at the end of Adriatic coastal seafaring and may have been a staple for products exchanged in Adriatic trade networks as well. Rocavecchia, therefore, was a pivot between the network of the Ionian Sea involving both northwestern Greece and the Gulf of Taranto and that of the Adriatic Sea. In the same way Sicilian Thapsos was pivotal between the Ionian Sea and Tyrrhenean networks, whilst the island of Vivara in the Bay of Naples may have been a staple for goods coming from Sardinia, Campania, Latium and Etruria.

Increased complexity is not only found in socio-political spheres and in the regional economies of southern Italy. It is equally present in the products made by artisans. The ceramic production of the Late Bronze Age, for instance, was rather varied: the traditional handmade impasto wares, the new wheelmade Italo-Mycenaean, wheelmade Italo-Minyan and wheelmade doli cordonati. Some of these ceramics required new techniques and served the new purposes of a new clientele. Similar observations can be made concerning the production of bronze objects. In the Late Bronze Age endogenous change and external influences cooperated in creating societies that were more populous, more strictly organized and more productive than groups living in southern Italy in earlier periods.

These data also suggest that the landscape changed considerably. This observation holds especially good for a wide coastal strip of southern Italy. Substantial fortifications and large tumuli and dolmens were conspicuous markers in this new landscape. This area harboured an unprecedented number of people producing unprecedented quantities of agricultural products. These must have come from intensely tilled fields, vineyards and olive groves that covered many more square miles than in any preceding period of south-Italian history. This suggests that land reclamation took place on a considerable scale and that wild nature was replaced by manmade environments in many places. Since palynological data are very scant for the Middle and Late Bronze Age, the human impact on the south-Italian landscape can only be discussed in very general lines in the present state of research. ${ }^{46}$

44 For the importance of metals, see Bietti Sestieri 1973; Matthäus 1980.There are remarkable similarities between the LBA and the early Iron Age trade and exchange networks. Salento (the eastern peninsula of Italy), eastern Sicily and the Bay of Naples figure prominently in both networks. This phenomenon may have something to do with prevailing winds and sea currents. In the LBA the Adriatic circuits were closely linked to these trade networks. In the Iron Age nonGreek trade networks were dominant in the Adriatic between the 8th and the late 6th century BC (cf. Yntema 1979).

45 For Baltic amber, see Vagnetti 1979, and Bietti Sestieri 1982.

46 Harding 1999; Di Rita / Magri 2009. 

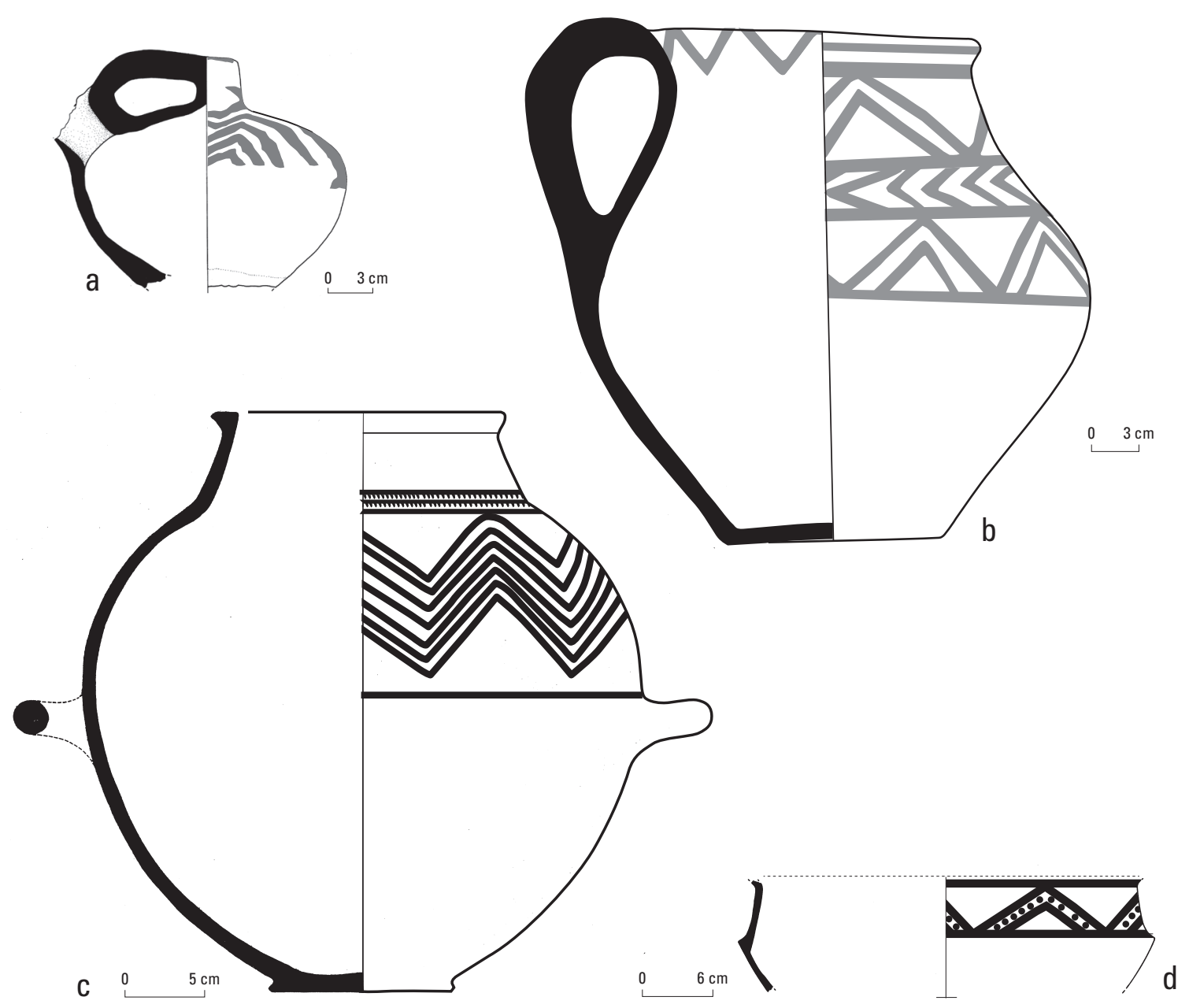

Fig. 2.12. South-Italian Protogeometric wares from Torre Castelluccia (b-c) and Leuca-Punta Meliso, south-Apulia (a and d). After Gorgoglione 1993 and D’Andria et al. 1990.

\subsection{THE FINAL BRONZE AGE (C. I I 5O-9OO B C)}

After the decline and the disappearance of the Aegean palace economies at c. $1200 \mathrm{BC}$ the contacts between Mycenaean Greece and southern Italy gradually lost their intensity. Since these were one of the vital aspects that contributed to the rise of the complex LBA centres of southern Italy, their gradual decrease had serious consequences for the coastal groups in the long run. The collection and storage of large surpluses and the exchange of surplus articles depended at least partly on external, transmarine contacts. When these contacts became increasingly less frequent and less intensive, these activities were no longer carried out. This means that the complex redistribution systems that supported these actions, were no longer required. The same holds good for the elites that were at the top of the hierarchically structured LBA societies and that were spiders in the redistribution webs. Their abilities to control larger areas and muster considerable surpluses from these were of little importance in situations where regulated, large scale exchange was no longer practiced and where long distance contacts had lost much of their frequency and intensity.

This period of gradually decreasing complexity that covers approximately the 12th and 11th century BC is usually indicated in Italy with the term Bronzo Finale (here: Final Bronze Age; FBA). It is hard 


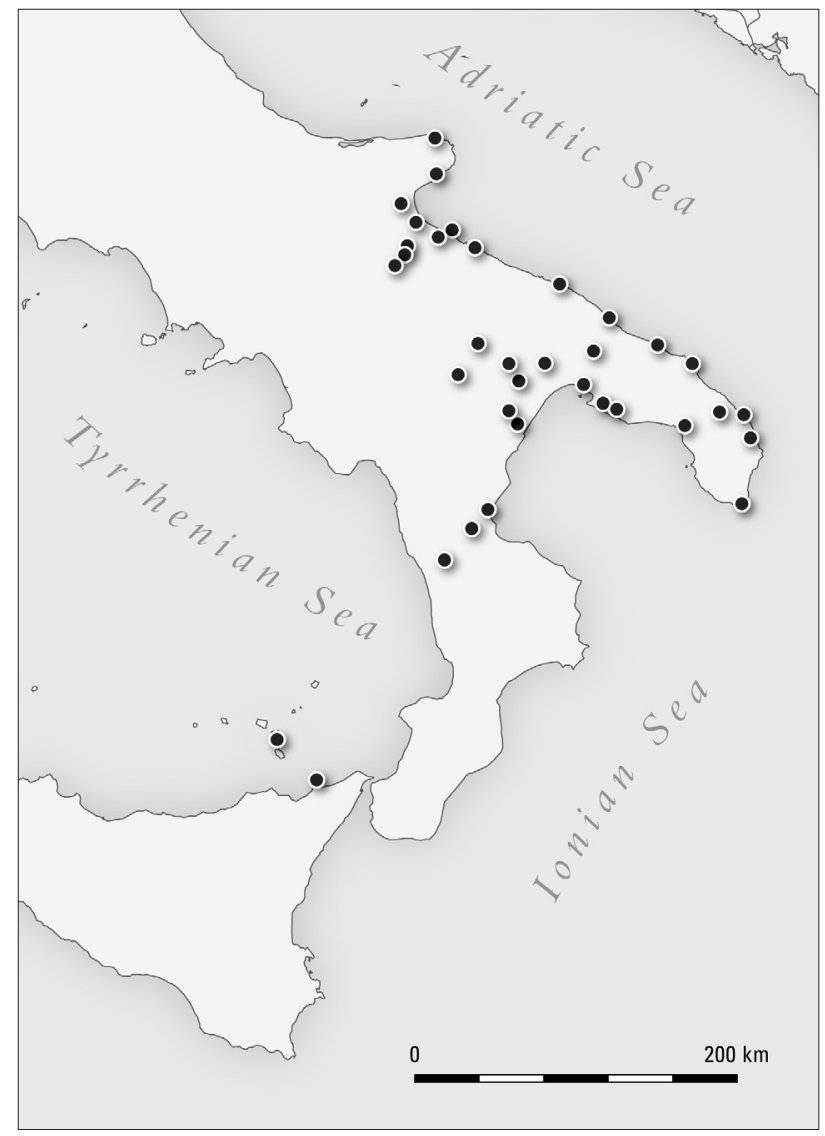

Fig. 2.13. Distribution of South-Italian Protogeometric wares (late 12th -10 th century BC).

to get a good grip on this period because - as we have seen above - it is on the watershed between two traditional academic domains: that of the prehistorians (Italian: paletnologi) on the one hand and that of the classical archaeologists on the other hand. An additional problem is the poor diagnostic qualities of the artefactual evidence. This transitional period between the Bronze Age and the Iron Age, moreover, displays a material culture that - quite understandably - has parallels in both the preceding and the subsequent period. This means that there is a persistent tendency to date objects and the excavational features in which they were found to either the preceding Late Bronze Age or the following Early Iron Age. The Final Bronze Age, therefore, is a period with a decidedly low visibility rate.

The decrease in complexity that supposedly characterizes the Final Bronze Age is suggested by various data. It is, for instance, clear that in the course of the 11th to 10th century BC the fairly contracted and walled, relatively populous settlements of the Late Bronze Age began to change into increasingly dispersed villages. Moreover, from about the 11th century some of these probably had a limited quantity of inhabitants numbering only a few dozens of persons, whilst the major LBA settlements can be assumed to have harboured at least several hundreds of inhabitants. In the area north of Brindisi the fortified LBA settlement of Risieddi was even completely abandoned and replaced by highly dispersed FBA occupation nearby. ${ }^{47}$ Reports suggest that many of the walled LBA sites were completely deserted in the Final Bronze Age, but on closer inspection most settlements appear to display signs suggesting continuity of occupation (albeit much less intense) to well within the Iron Age.

The settlements of the Final Bronze were not exclusively declining centres with MBA or LBA origins. In approximately the 10th century BC (but the diagnostic qualities of the artefacts are limited) new settlements came into being in some parts of southeast Italy. The information on this subject is still scant, because settlement survey has rarely been carried out. The reports published hitherto suggest that this happened in any case in northern Apulia. Here the lagoon settlements of Siponto and Salapia are reported to have their origins in the Final Bronze Age. ${ }^{48}$ sanctuary

More signs suggesting the gradual transition to less complex societies can be found in the pottery production of the Final Bronze Age. Whilst the Late Bronze Age is characterized by the coexistence of traditional handmade 'Subapennine' impasto wares and various wheelmade wares of Mycenaean type, the Final Bronze Age witnessed the gradual but complete disappearance of wheelmade pottery. ${ }^{49}$ Although the large dolia continued to be made for some time, ${ }^{50}$ the 'Subapennine' impasto ceramics

47 Attema et. al 2010, 112

48 De Juliis 1979 (Siponto); Alberti et al. 1981 (Salapia).
49 Boccuccia et al. 1998.

50 Vagnetti 1999. 


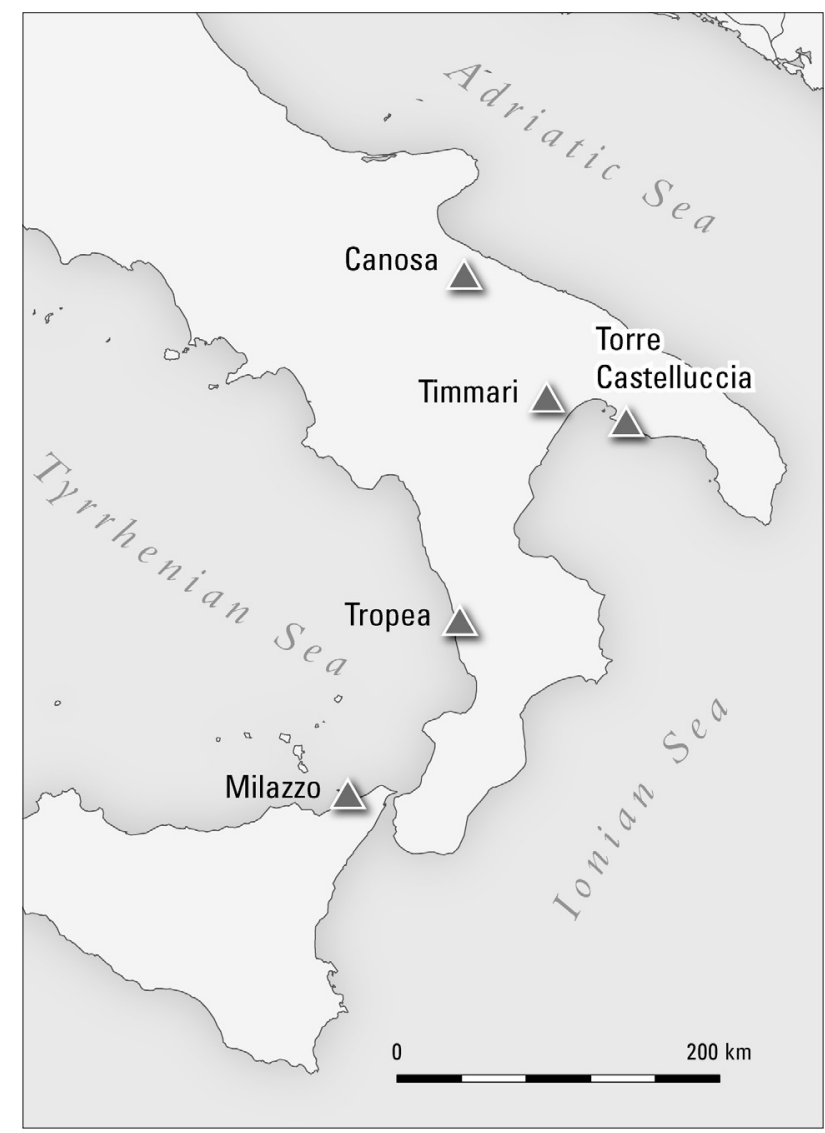

Fig. 2.14. Urnfields in southeast Italy; Late Bronze Age and Final Bronze Age.

transformed into the so-called Protovillanovan impasto wares in quite an early stage of the Final Bronze Age. These show no technical innovations, but display a series of new shapes that are the prototypes of the Iron Age repertory of forms. ${ }^{51}$

Painted wares can also be found in the Final Bronze Age. These are the so-called South-Italian Protogeometric wares. This class of handmade ceramics with dark, mattpainted ornaments on a light background has nothing to do with Greek Protogeometric wares. It was probably a cross between impasto wares and Italo-Mycenaean. ${ }^{52}$ The shapes and the painted ornaments of this class display close affinities with both the forms and the incised ornaments of Protovillanovan wares. The idea of making ceramics with dark ornaments on a whitish to yellowish clay was borrowed from the most recent ceramics of Mycenaean type found in Italy (fig. 2.12). South-Italian Protogeometric was almost certainly made in various parts of the coastal areas of southeast Italy. The uniformity in the morphological and decorative language of these painted wares over large parts of southern Italy suggests that interregional contacts within this area continued to be relatively frequent. A similar impression is conveyed by the distribution of the same ceramic class (fig. 2.13). These wares were not only distributed over present-day Apulia, Basilicata and northern Calabria. South-Italian Protogeometric is also found in eastern Sicily and the Aeolian islands north of Sicily (e.g. Lipari) ${ }^{53}$ These wares were even imitated there..$^{54}$ This suggests that the FBA societies of southeast Italy were considerably more dynamic than is generally assumed. Whilst the contacts between southeast Italy and Greece may have lost much of their frequency, the contacts between the coastal areas of the Ionian Sea (including the eastern part of Sicily) continued to be fairly intense in the Final Bronze Age.

Burial sites securely dating to the Final Bronze Age are rare in southeast Italy. Hitherto only two necropoleis with graves dating to the period under discussion have been reported. They exclusively contain individual cremations: the ashes of the deceased were deposited in an impasto urn or SouthItalian Protogeometric matt-painted vessel. Such urnfields have been discovered at Timmari in the border area between Apulia and Basilicata and at Torre Castelluccia in the Taranto district (fig. 2.14). ${ }^{55}$

51 Cremonesi 1979; fig. 2.11.

52 Yntema 1990, Brigger 2007.

53 Eliane Brigger presented 101 fragments of South-Italian Protogeometric from the island of Lipari (Brigger 2007, 332-381).

54 Yntema 1990, 27: Brigger 2007.

55 The Canosa urnfield contained over 200 burials, see
Nava 1984, 117. For cremation tombs from Canosa, see Lo Porto 1969, 248, and Lo Porto 1992a; for cremations from Timmari, see Quagliati and Ridola 1900 and 1906; for cremations from Torre Castelluccia, see Müller-Karpe 1961 and Vanzetti 2002. Slightly outside the area discussed here are the contemporary cremation burial sites of Tropea (Calabria) and Milazzo (Sicily). 
The earliest burials in these cemeteries are likely to date to the Late Bronze Age. The characteristics of these necropoleis of the Final Bronze Age, therefore, have their roots in the Late Bronze Age. If urnfields were indeed the only type of FBA burial sites, something drastic happened in the funerary sphere. However, more research is needed in order to establish whether this indeed is the whole story. If, for instance, the LBA tumuli continued to be used for inhumations during the Final Bronze Age, the graves of this period in the tumuli - because of the poor diagnostic qualities of FBA artefacts - are hard to identify.

The general image of the Final Bronze Age of southern Italy is one of gradual change. The contacts with the eastern Mediterranean became much less frequent and intense, the conspicuous regional elites of the Late Bronze Age vanished or became invisible in the archaeological record. Population figures, moreover, declined, and the sophisticated redistribution systems displaying slight affinities with the palace economies of Mycenaean districts in the Aegean vanished completely. For all these reasons, the Final Bronze Age of southern Italy has been characterized as a Dark Age separating the prosperous Late Bronze Age from the humble beginnings of the south-Italian Iron Age. The evidence suggests that notwithstanding the fog caused by numerous bias factors surrounding this period of transition, there may be some truth in this view.

A similar observation, however, has almost never been made for the same period in any other part of Italy. In Sicily, for instance, the Ausonio II phase (11th-10th centuries) is never considered to be a FBA dip in comparison to the preceding, mainly LBA Ausonio I phase (13th-12th century), although complex Thapsos with its LBA warehouses has no parallels in the Sicilian Final Bronze Age. It seems therefore, that southeast Italy was an exception to the rule. Here the fairly complex society of the Late Bronze Age with its intense transmarine contacts, its redistribution systems and its powerful leaders gradually evolved into the less stratified, initially largely self-contained societies of the Early Iron Age. In this process of change the Final Bronze Age marks the first decisive steps. 
